\title{
Optimization of Honing Surface Roughness of Carburized Holes Based on GRA-RSM
}

\author{
Tao Tang ${ }^{1,2} \mathbb{D}$, Chi Liu ${ }^{1, *}$ and Rong Wang ${ }^{2}$ \\ 1 College of Mechanical and Electrical Engineering, Changsha University, Changsha 410114, China; \\ nbvcx163@163.com \\ 2 AVIC Power Zhuzhou Aviation Parts Manufacturing Co., Ltd., Zhuzhou 412002, China; \\ wangrong_0410@163.com \\ * Correspondence: liuchi@ccsu.edu.cn
}

check for updates

Citation: Tang, T.; Liu, C.; Wang, R Optimization of Honing Surface Roughness of Carburized Holes Based on GRA-RSM. Machines 2021, 9 , 291. https://doi.org/10.3390/ machines 9110291

Received: 9 October 2021

Accepted: 10 November 2021

Published: 16 November 2021

Publisher's Note: MDPI stays neutral with regard to jurisdictional claims in published maps and institutional affiliations.

Copyright: (c) 2021 by the authors. Licensee MDPI, Basel, Switzerland. This article is an open access article distributed under the terms and conditions of the Creative Commons Attribution (CC BY) license (https:// creativecommons.org/licenses/by/ $4.0 /)$.

\begin{abstract}
The carburized holes processed by ordinary internal grinding are prone to burn, crack, and low efficiency. Honing has a superior machining efficiency and cooling effect compared to traditional internal grinding. In this paper, we innovatively apply honing to carburizing hole grinding and propose an effective optimization scheme to enhance the surface finish of carburized holes. We set up an experimental system to explore the influence law of honing head rotation speed, axial reciprocating speed, grain size, and single grinding depth on surface roughness. Based on the grey correlation and response surface method, we propose a method to optimize the honing parameters of carburized holes and establish a prediction model, which has an $\mathrm{R}^{2}$ value of 0.9887 , indicating that the model fits well. We verify the validity of the model by the root mean square error of 0.012 between the measured and calculated values. Based on the model, the optimal parameters of roughness (Ra) is obtained and verified by experiments. Compared with the original honing parameters, the surface roughness quality is improved by $25.8 \%$. It shows that the optimized honing process based on the GRA-RSM method improves the surface quality of carburized holes significantly.
\end{abstract}

Keywords: carburizing hole; honing; grey relational analysis; response surface method; optimization

\section{Introduction}

Carburized alloy, an essential material for aero-engines, which is hard on the outside and tough on the inside, is used for wear parts that withstand impacts. After carburizing and hardening, it gains good wear resistance and is often machined on an internal grinder. However, if the machining efficiency is low, the parts are prone to burns and micro-cracks. This is due to the instantaneous high temperature in the grinding zone, which exceeds the martensitic transformation initiation temperature (TMS) or the austenitic transformation end temperature (TAc3), and cools rapidly. It leads to oxidation discoloration and tissue changes on the surface [1]. Honing is an industrial alternative to internal grinding [2]. The honing process, a face contact grinding method, has the advantages of high machining efficiency and high precision, which can obtain good surface roughness [3,4]. After the machining of carburized holes by honing technology, the workpiece has no burn and crack problems, and the machining efficiency is significantly improved. In honing, with relatively low cutting speed of a single abrasive grain and small heat flux, the workpiece surface is less likely to burn. Honing technology can make up for the shortcomings of the existing internal grinding technology, and thus is widely used in precision hole processing. Lu et al. [5] utilized a topological optimization technique to modify the composition structure of oilstone to reduce environmental pollution. Grover and Singh [6] developed a modified magneto-rheological honing technique to achieve nano-scale finishing. The authors of $[2,7]$ reviewed the application of honing technology in the machining of internal combustion engine cylinders, analyzed the surface wear mechanism, and concluded that the size and 
the shape of the abrasive grains mainly affect the surface quality. Buj-Corral et al. [8] investigated the effect of abrasive density on process parameters and concluded that the oilstone density was selected according to the acoustic emission of the grinding. The authors of [9-11] investigated the application of honing techniques in hardened steel, $\mathrm{CuNiCr}$ copper-nickel alloy, analyzed the effects of honing angle and abrasive size on roughness and residual stress, and finally obtained the optimized process parameters. Muratov and Muratov et al. [12] studied the honing technology of $95 \mathrm{Cr} 18$ and $12 \mathrm{CrNi} 3 \mathrm{~N}$ hydraulic components, analyzed the effect of honing track mesh density on surface roughness, and determined the control mechanism of mesh density. Yang and Su et al. [13] applied the honing technology to the essential parts of the fuel nozzles of aero-engines, established the honing cutting force model, and obtained the optimal surface honing process.

A scientific and reasonable method is necessary to obtain the optimal honing parameters. The response surface method, proposed by Box and Wilson [14], is a combination of statistical methodology and mathematical methods. The response surface method establishes a second-order response surface model by fitting the mathematical relationship between multiple influencing factors and response variables to determine the best combination to obtain the optimal response within the experimental design planning. Recently, Nguyen et al. [15] used the response surface method and genetic algorithms to calculate the relationship between grain size, tangential velocity, and linear velocity on the target to improve surface performance and productivity. Sadizade et al. [16] studied the honing process parameters of automobile cylinders, established an optimization function model, and obtained the honing processing time with minimum surface roughness. Lawrence et al. [17] used the Taguchi method to improve the processes of coarse honing and finish honing, as well as those of other stages. The response surface method has a variety of experimental design types. The Central Composite Design (CCD) and Box-Behnken Design (BBD) are suitable for assessing the nonlinear effects of factors. CCD and BBD provide quantitative analysis and evaluation of the relationship between multiple influencing factors and their interactions with response variables, which are now successfully applied to develop, improve, and optimize processes [18]. Ciggin et al. [19] studied the advanced oxidation treatment of municipal wastewater and designed CCD experiments to derive the optimal treatment protocol. Sindhu et al. [20] studied the honing process of quartz glass and obtained the ideal process using the response surface method.

However, there are few studies in the existing literature on honing of carburized holes in alloy steel $12 \mathrm{Cr} 2 \mathrm{Ni} 4 \mathrm{~A}$. This study aims to obtain the optimal process for carburized holes with the minimum Ra value. In this paper, the research object is the tappet guide sleeve used in an engine. We adopt the GRA-RSM method to study the honing process of carburized holes and establish the optimization model to accurately calculate the surface Ra value of carburized holes and finally obtain the optimal parameter combination.

\section{Experiment and Method}

\subsection{Experimental Subject and Instruments}

The experiment was carried out on the horizontal honing machine (Name: Precision Horizontal Honing Machine, Model: HM-2000, Origin: Xinneng Precision Machinery Co., Ltd., Suzhou, China). The honing workpiece is $18 \mathrm{Cr} 2 \mathrm{Ni} 4 \mathrm{~W}$ carburized alloy steel with an inner hole size of $20 \times 150 \mathrm{~mm}$. The specific parameters are listed in Table 1 . The total number of test pieces was 80 , and the total number of test groups was 40 (including: 16 orthogonal experiments, 17 BBD experiments, and 7 comparison experiments). Two samples were tested per test group and each sample was measured twice. The average of the measurements of all samples in each group was taken as the final result for that group. 
Table 1. Workpiece parameters.

\begin{tabular}{cccccc}
\hline Items & $\begin{array}{c}\text { Material } \\
\text { Trademark }\end{array}$ & $\begin{array}{c}\text { Surface Heat } \\
\text { Treatment }\end{array}$ & Ra Value $(\mu \mathrm{m})$ & $\begin{array}{c}\text { Pore Size before } \\
\text { Honing }(\mathbf{m m})\end{array}$ & $\begin{array}{c}\text { Pore Size after } \\
\text { Honing }(\mathbf{m m})\end{array}$ \\
\hline \multirow{2}{*}{ Parameters } & 12Cr2Ni4A & $\begin{array}{c}\text { Carburizing }+ \\
\text { quenching }(\mathrm{HRC} \geq 60)\end{array}$ & $\leq 0.8$ & $\Phi 20 \pm 0.005$ & $\Phi 20.05 \pm 0.005$ \\
\hline
\end{tabular}

A new CBN oilstone (model K20) was used for each group of tests to avoid the influence of wear. The honing cooling oil (model HM-2) was adopted to eliminate dry grinding. The honing movement includes the spindle rotation of the honing head and the reciprocating motion of the workpiece along the axial direction. The experimental equipment is shown in Figure 1. The internal structure of the honing head is shown in Figure 2.

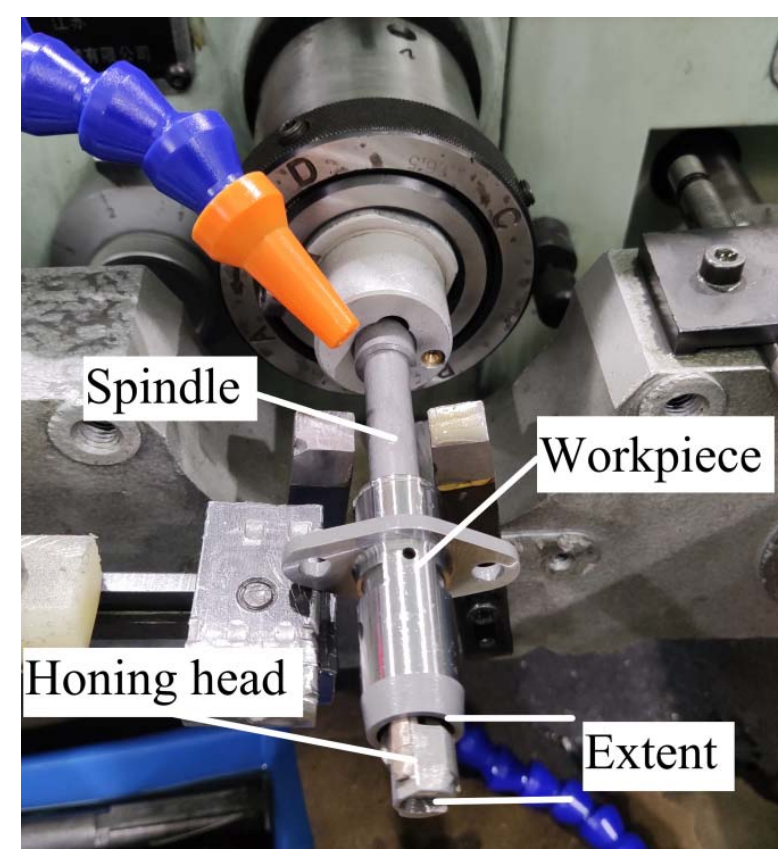

Figure 1. Honing experimental equipment.

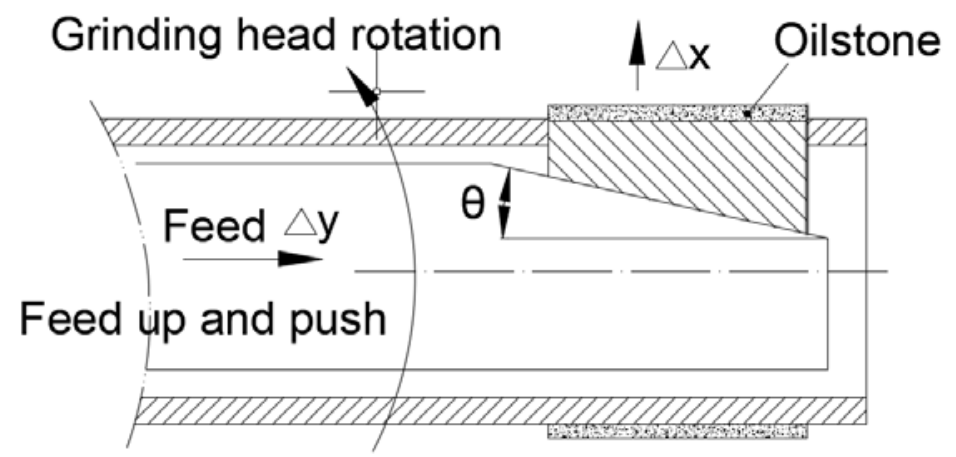

Figure 2. Schematic diagram of honing head structure.

The oil-stone feed $(\Delta x)$ is completed by the push rod feed $(\Delta y)$ wedge action on the oilstone, and the relationship between $\Delta \mathrm{x}$ and $\Delta \mathrm{y}$ is shown in Formula (1):

$$
\tan \theta=\frac{\Delta \mathrm{x}}{\Delta \mathrm{y}}
$$


A roughness profilometer (Name: High-precision contour measuring system, model: Waveline W800, Origin: HommelWerke Co., Ltd., Villingen-Schwenningen, Germany) was applied to measure the surface Ra value of carburized holes. The measuring range was 0 200 mm, and resolution was $0.01 \mu \mathrm{m}$. The measuring equipment is shown in Figure 3 . Measurement of surface roughness was in accordance with International Standard ISO 1302-2002 (Geometrical Product Specifications (GPS) - Indication of surface texture in technical product documentation).

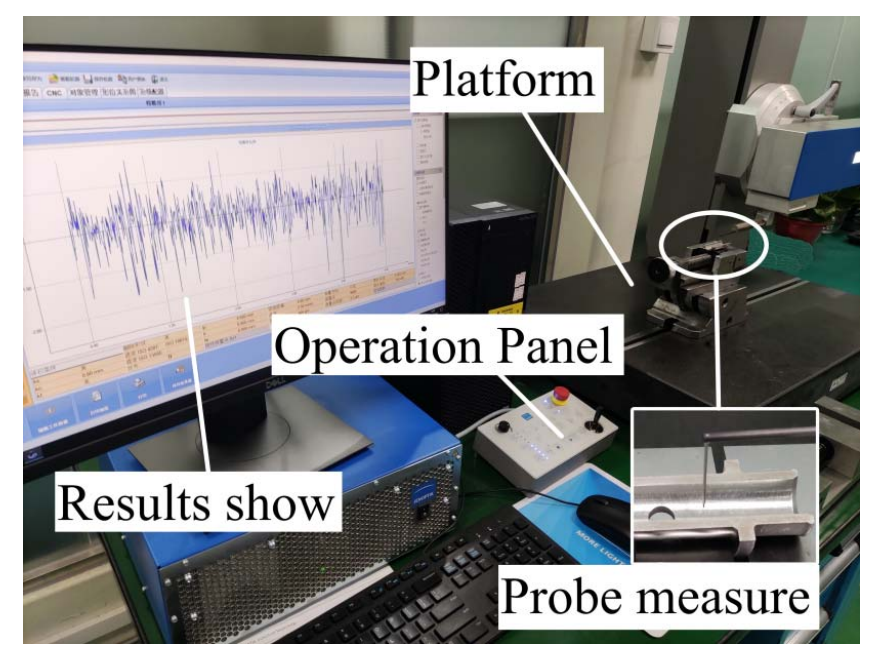

Figure 3. Roughness profilometer.

The main parameters for the definition of surface roughness are $\mathrm{Ra}, \mathrm{Rz}$, or $\mathrm{Ry}$. $\mathrm{Rz}$ only reflects the peak height of the profile and does not reflect the sharp or flat geometric characteristics of the peak. The measurement is influenced by subjective factors of the measurer and the results are not accurate enough. Ry is the sum of the perpendicular distances from the highest and lowest points to the center line of the ten points of microscopic unevenness, so it is not as accurate as the geometric properties reflected by the Rz value. However, according to standard ISO 4287-1997, $\mathrm{Ra}$ is the arithmetic mean of the absolute value of the profile offset within the sampling length, L (as shown in Figure 4). Equation (2) is the formula for calculating the Ra value. It can fully reflect the characteristics of the surface micro-geometry in terms of height. The stylus method of measuring Ra values, which can be read automatically by the machine, is highly efficient and accurate. Internationally, $\mathrm{Ra}$ is generally preferred among the basic roughness assessment parameters. Therefore, Ra has been used as the criterion for surface roughness in this paper.

$$
\mathrm{Ra}=\frac{1}{\mathrm{~L}} \int_{0}^{\mathrm{L}}|\mathrm{y}(\mathrm{x})| \mathrm{dx} \text {. }
$$

where, the contour offset $y$ is the distance between the contour point and the datum line in the measurement direction. The datum line is the least squares midline of the profile.

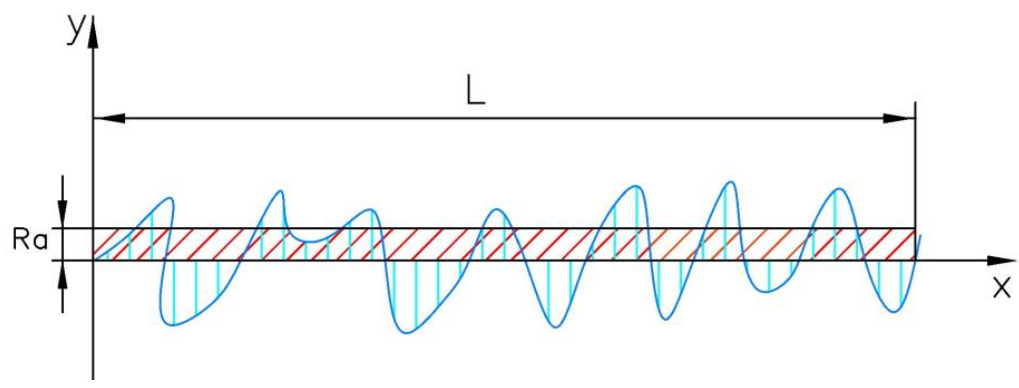

Figure 4. Parameters for evaluating surface roughness. 


\subsection{Experimental Method}

In this paper, the oil-stone grinding grain size, $\mathrm{P}$, single grinding depth, $\Delta \mathrm{x}$, grinding head rotation speed, $\mathrm{V}_{1}$, and reciprocating speed, $\mathrm{V}_{2}$, were selected as input parameters, and roughness, $\mathrm{Ra}$, as the output variable. In each group of experiments, the workpiece was machined to a desired size (see Table 1 for dimensions), and data were recorded. The relationship between process parameters and response variables was analyzed qualitatively by the grey relational degree method. Then, based on response surface methodology, the quantitative relationship between each parameter and roughness ( $\mathrm{Ra})$ value was further analyzed, and a mathematical model was established. Finally, the optimal honing process parameters with minimum surface roughness were obtained. The optimization process is shown in Figure 5.

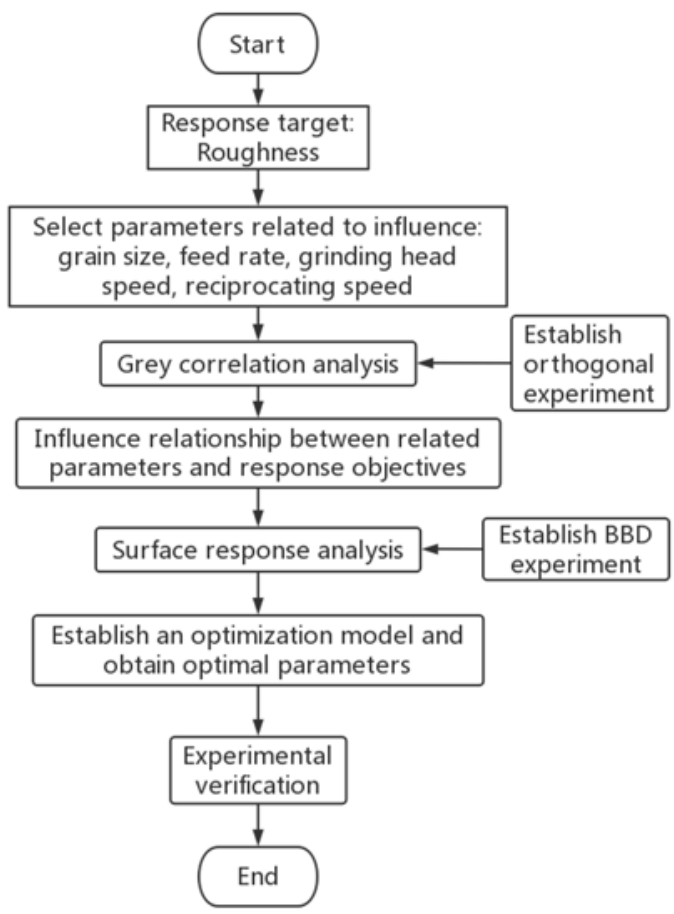

Figure 5. The optimization process chart.

\section{Grey Relational Analysis}

Grey relational grade analysis (GRA), widely used in the machining field, is a method to judge the strong correlation between parameters according to the degree of change trend of each parameter [21-23]. Grey correlation analysis based on orthogonal experiments usually includes the following steps: (i) Build an orthogonal experimental plan and complete the test. (ii) The SNR of response variables is calculated to replace the evaluation index of product robustness. (iii) Data are normalized. (iv) The grey correlation coefficient, $\zeta$, and the correlation degree, $\gamma$, of the normalized values are calculated. (v) Calculate the range value and analyze the influence law of relevant parameters.

\subsection{The Calculation of SNR}

Signal-to-noise ratio (SNR), the core of parameter design, is an index used to measure quality in robust design. Yang [24] noted that the basic idea is to select the best-level combination of all parameters in the system so that the designed product has strong antiinterference, low fluctuation of product quality characteristic value, and good robustness. 
For honing, the characteristic quantity is surface roughness, Ra. The smaller the Ra value, the better the surface quality. The calculation formula of SNR is shown in Formula (3):

$$
\delta_{\mathrm{i}}=-10 \lg \left(\frac{1}{\mathrm{n}} \sum_{\mathrm{i}=1}^{\mathrm{n}} \mathrm{x}_{\mathrm{i}}^{2}\right)
$$

In the formula, $n$ represents the number of repetitions of the group of experiments, $x_{i}$ denotes the result of the ith experiment, and $\delta_{i}$ is the SNR of the group of experiments. The L4(4) orthogonal experiment was established to qualitatively analyze the effects of various parameters on the Ra value. Considering the actual processing efficiency, the grain size $(\mathrm{P})$ of the honing oilstone was selected from four commonly used grain sizes: 60, 100, 400, and 600 mesh. For example, 400 mesh means 400 holes per inch, and the larger the mesh, the finer the particle. Combined with the actual maneuverability, the single grinding depth, $\Delta \mathrm{x}(\mathrm{mm})$, was $0.005,0.008,0.015$, and 0.025 , respectively. Then, according to the parameter range of experimental equipment, the grinding head rotation speed, $V_{1}(\mathrm{r} / \mathrm{min})$, was 50, 100,150 , and 200, and the reciprocating speed of the workpiece, $V_{2}$ (m/min), was 20, 30, 40, and 50. An orthogonal test was carried out, and the specific parameters are shown in Table 2.

Table 2. Orthogonal experimental design.

\begin{tabular}{|c|c|c|c|c|}
\hline Experiment & $\begin{array}{c}\text { Grinding Head } \\
\text { Rotation Speed, } \\
\quad V_{1}(\mathrm{r} / \mathrm{min})\end{array}$ & $\begin{array}{c}\text { Average Particle } \\
\text { Size of } \\
\text { Oilstone, P } \\
\text { (mesh) }\end{array}$ & $\begin{array}{l}\text { Workpiece } \\
\text { Reciprocating } \\
\text { Speed, } \mathrm{V}_{2} \\
(\mathrm{~m} / \mathrm{min})\end{array}$ & $\begin{array}{c}\text { Single } \\
\text { Grinding } \\
\text { Depth, } \Delta x(\mathrm{~mm})\end{array}$ \\
\hline 1 & 50 & 60 & 20 & 0.005 \\
\hline 2 & 50 & 100 & 30 & 0.008 \\
\hline 3 & 50 & 400 & 40 & 0.015 \\
\hline 4 & 50 & 600 & 50 & 0.025 \\
\hline 5 & 100 & 60 & 30 & 0.015 \\
\hline 6 & 100 & 100 & 20 & 0.025 \\
\hline 7 & 100 & 400 & 50 & 0.005 \\
\hline 8 & 100 & 600 & 40 & 0.008 \\
\hline 9 & 150 & 60 & 40 & 0.025 \\
\hline 10 & 150 & 100 & 50 & 0.015 \\
\hline 11 & 150 & 400 & 20 & 0.008 \\
\hline 12 & 150 & 600 & 30 & 0.005 \\
\hline 13 & 200 & 60 & 50 & 0.008 \\
\hline 14 & 200 & 100 & 40 & 0.005 \\
\hline 15 & 200 & 400 & 30 & 0.025 \\
\hline 16 & 200 & 600 & 20 & 0.015 \\
\hline
\end{tabular}

The distribution of workpiece bore roughness is not uniform, and the cylindrical surface of the bore has a large taper. Therefore, multiple groups of experiments were conducted with the extension of the oilstone (i.e., the length of the oilstone sticking out from the two-end face of the workpiece, and one extension is shown in Figure 1). The three groups of extensions were 10, 20, and $30 \mathrm{~mm}$ (the total length of the oilstone is $60 \mathrm{~mm}$ ), respectively. The SNR values of each group are calculated by Equation (3), with the results recorded in Table 3.

Table 3. Grey correlation analysis results.

\begin{tabular}{|c|c|c|c|c|c|c|c|c|c|c|}
\hline \multirow[t]{2}{*}{ Experiment } & \multicolumn{3}{|c|}{$\begin{array}{l}\text { Average Roughness of } 10 \mathrm{~mm} \\
\text { Extension }\end{array}$} & \multicolumn{3}{|c|}{$\begin{array}{c}\text { Average Roughness of } 20 \mathrm{~mm} \\
\text { Extension }\end{array}$} & \multicolumn{3}{|c|}{$\begin{array}{c}\text { Average Roughness of } 30 \mathrm{~mm} \\
\text { Extension }\end{array}$} & \multirow[t]{2}{*}{$\gamma$} \\
\hline & $\delta$ & $x$ & $\xi$ & $\delta$ & $x$ & $\xi$ & $\delta$ & $x$ & $\xi$ & \\
\hline 1 & -4.082 & 0.722 & 0.409 & -4.657 & 0.705 & 0.415 & -4.807 & 0.703 & 0.416 & 0.413 \\
\hline 2 & -6.411 & 0.491 & 0.505 & -6.783 & 0.481 & 0.510 & -7.576 & 0.440 & 0.532 & 0.516 \\
\hline
\end{tabular}


Table 3. Cont.

\begin{tabular}{|c|c|c|c|c|c|c|c|c|c|c|}
\hline \multirow[t]{2}{*}{ Experiment } & \multicolumn{3}{|c|}{$\begin{array}{c}\text { Average Roughness of } 10 \mathrm{~mm} \\
\text { Extension }\end{array}$} & \multicolumn{3}{|c|}{$\begin{array}{c}\text { Average Roughness of } 20 \mathrm{~mm} \\
\text { Extension }\end{array}$} & \multicolumn{3}{|c|}{$\begin{array}{l}\text { Average Roughness of } 30 \mathrm{~mm} \\
\text { Extension }\end{array}$} & \multirow[t]{2}{*}{$\gamma$} \\
\hline & $\delta$ & $\mathbf{x}$ & $\xi$ & $\delta$ & $\mathbf{x}$ & $\xi$ & $\delta$ & $x$ & $\xi$ & \\
\hline 3 & -8.090 & 0.358 & 0.582 & -7.250 & 0.438 & 0.533 & -9.020 & 0.332 & 0.601 & 0.572 \\
\hline 4 & -10.722 & 0.197 & 0.718 & -11.341 & 0.150 & 0.769 & -13.112 & 0.109 & 0.821 & 0.769 \\
\hline 5 & -3.809 & 0.753 & 0.399 & -3.675 & 0.829 & 0.376 & -4.365 & 0.753 & 0.399 & 0.391 \\
\hline 6 & -5.099 & 0.613 & 0.449 & -5.917 & 0.565 & 0.469 & -6.267 & 0.554 & 0.475 & 0.464 \\
\hline 7 & -9.244 & 0.281 & 0.640 & -9.499 & 0.263 & 0.655 & -10.034 & 0.267 & 0.652 & 0.649 \\
\hline 8 & -11.869 & 0.140 & 0.781 & -12.217 & 0.104 & 0.827 & -14.657 & 0.049 & 0.911 & 0.840 \\
\hline 9 & -1.917 & 1.000 & 0.333 & -2.476 & 1.000 & 0.333 & -2.476 & 1.000 & 0.333 & 0.333 \\
\hline 10 & -5.730 & 0.552 & 0.475 & -6.614 & 0.496 & 0.502 & -7.190 & 0.471 & 0.515 & 0.497 \\
\hline 11 & -9.499 & 0.266 & 0.653 & -8.995 & 0.299 & 0.626 & -9.499 & 0.300 & 0.625 & 0.635 \\
\hline 12 & -15.598 & 0.000 & 1.000 & -14.610 & 0.000 & 1.000 & -16.138 & 0.000 & 1.000 & 1.000 \\
\hline 13 & -4.041 & 0.726 & 0.408 & -3.768 & 0.816 & 0.380 & -4.322 & 0.758 & 0.397 & 0.395 \\
\hline 14 & -7.151 & 0.429 & 0.538 & -7.351 & 0.429 & 0.538 & -7.766 & 0.424 & 0.541 & 0.539 \\
\hline 15 & -7.618 & 0.393 & 0.560 & -7.618 & 0.406 & 0.552 & -8.046 & 0.403 & 0.554 & 0.555 \\
\hline 16 & -12.217 & 0.124 & 0.801 & -11.213 & 0.157 & 0.761 & -13.765 & 0.082 & 0.859 & 0.807 \\
\hline
\end{tabular}

$\delta$ : SNR. x: The dimensionless value. $\xi$ : Grey correlation coefficient. $\gamma$ : Grey relational degree.

\subsection{Grey Relational Degree Calculation}

Based on the grey correlation analysis method, the original data were firstly normalized, and then the grey correlation coefficients of the normalized data and the ideal state data were calculated. Finally, the grey correlation degree was calculated. In this paper, we normalized the data using the dimensional normalization method. The normalization formula is shown in Formula (4):

$$
\mathrm{x}_{\mathrm{i}}=\frac{\delta_{\mathrm{i}}-\min \delta_{\mathrm{i}}}{\max \delta_{\mathrm{i}}-\min \delta_{\mathrm{i}}}
$$

In the formula: $\delta_{i}$ denotes the SNR of group $i$ experiment, and $x_{i}$ represents the value after dimensionalization.

The grey correlation coefficient is calculated as shown in Formula (5):

$$
\xi_{i}=\frac{\min \left|x_{i}^{0}-x_{i}\right|+\lambda \max \left|x_{i}^{0}-x_{i}\right|}{\left|x_{i}^{0}-x_{i}\right|+\lambda \max \left|x_{i}^{0}-x_{i}\right|}
$$

where $\lambda$ refers to the resolution coefficient, with a value range of $[0,1]$ and a general value of 0.5 , and $x_{i}^{0}$ denotes the ideal parameter of the evaluation data. The evaluation target in this paper is roughness, and the ideal value $x_{i}^{0}=0$ is used for calculation.

Based on Formula (4) and (5), the grey correlation degree can be calculated as shown in Formula (6) below:

$$
\gamma_{\mathrm{i}}=\frac{1}{\mathrm{n}} \sum_{\mathrm{i}=1}^{\mathrm{n}} \xi_{\mathrm{i}}
$$

where $\gamma_{\mathrm{i}}$ denotes the grey correlation degree of the experiment in group $\mathrm{i}$, and $\mathrm{n}$ represents the number of repeated experiments in this group.

In Table 3, it can be seen that the greater the grey correlation degree value, the smaller the surface roughness value obtained by this set of parameters, and vice versa.

\subsection{Data Analysis and Discussion}

According to the comprehensive average grey degree in Table 3, we calculated the range-value of each parameter level, as shown in Table 4. The larger the $\mathrm{Q}$ value, the more significant the impact. Therefore, according to the order of the $Q$ value, the order of influencing Ra values is as follows: the average particle size of the whetstone $(P)>$ the single grinding depth $(\Delta x)>$ the grinding head rotation speed $\left(V_{1}\right)>$ the reciprocating 
speed of the workpiece $\left(\mathrm{V}_{2}\right)$. Then, according to the parameter value corresponding to the maximum grey correlation value in the orthogonal experiment, the optimal parameters of roughness were obtained as follows: oilstone size 600 mesh, single grinding depth $0.05 \mathrm{~mm}$, grinding head speed $150 \mathrm{r} / \mathrm{min}$, and workpiece reciprocating speed $30 \mathrm{~m} / \mathrm{min}$.

Table 4. Grey correlation at all levels.

\begin{tabular}{ccccc}
\hline Levels & $\begin{array}{c}\text { Grinding Head } \\
\text { Rotation Speed } \\
(\mathbf{r} / \mathbf{m i n})\end{array}$ & $\begin{array}{c}\text { Grind Grain } \\
\text { Size (mesh) }\end{array}$ & $\begin{array}{c}\text { Workpiece } \\
\text { Reciprocating } \\
\text { Speed (m/min) }\end{array}$ & $\begin{array}{c}\text { Single } \\
\text { Grinding Depth } \\
(\mathbf{m m})\end{array}$ \\
\hline K1 & 0.568 & 0.383 & 0.58 & 0.65 \\
K2 & 0.586 & 0.504 & 0.616 & 0.597 \\
K3 & 0.616 & 0.603 & 0.571 & 0.567 \\
K4 & 0.574 & 0.854 & 0.578 & 0.53 \\
Q & 0.048 & 0.471 & 0.045 & 0.12 \\
\hline
\end{tabular}

The experimental results obtained with the extensions of 10,20, and $30 \mathrm{~mm}$ are shown in Figure 6. Extent_10 mm, Extent_20 mm, and Extent_30 $\mathrm{mm}$ represent the Ra values obtained after 16 groups of experiments in which the distance between the grinding head and the workpiece end face is 10, 20,30 mm, respectively. Using the Coordinate Measuring Machine (Name: Bridge Type CMM, Model: ZEISS CONTURA, Origin: Carl Zeiss AG, Oberkochen, Germany) to measure the cylindricity of the bore, when the projection is $20 \mathrm{~mm}$, the cylindricity of the workpiece is significantly better than that of the remaining two groups, as shown in Figure 7. There are two reasons: (i) When the extension is $10 \mathrm{~mm}$, grind time near the two ends is less than that in the middle position, so the grinding amount at the two ends is less than that at the central part, and the final cylindrical surface forms a waist drum shape with two small ends and a large middle. (ii) When the extension is $30 \mathrm{~mm}$, it is half of the total length of the oilstone. After the grinding head swells, the extension is in an unconstrained state. During the reciprocating movement of the grinding head, and long grinding time at both ends, the impact friction of the oilstone on the hole walls at both ends of the workpiece increases, and the oilstone wears quickly, resulting in more removal allowance. Therefore, the hole surface is in the shape of a bell mouth with two big ends and a small middle.

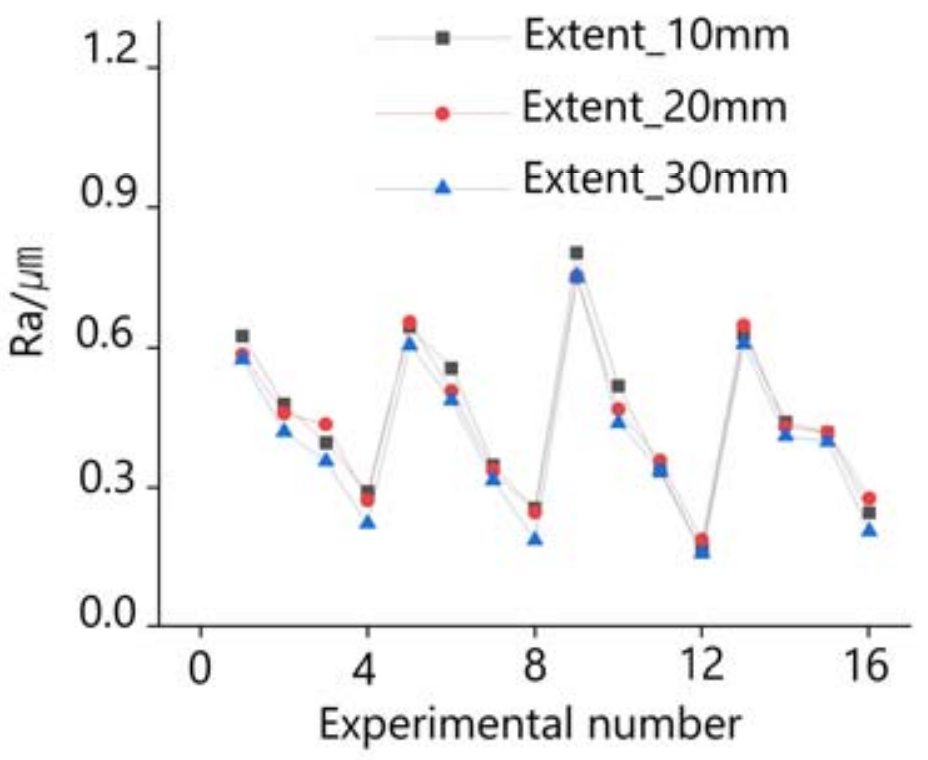

Figure 6. Comparison chart of multi-group experimental results. 


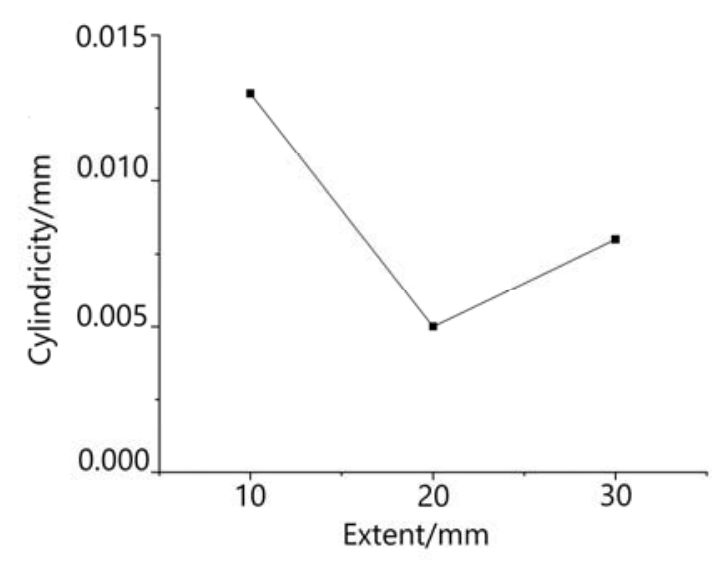

Figure 7. Cylindricity of different extensions.

\section{Response Surface Regression}

Earlier in the article, we qualitatively analyzed the association between honing parameters and response Ra values based on grey correlation analysis, and also obtained the optimized parameter combinations. However, experimental parameters that are outside the orthogonal experiment cannot be performed in the orthogonal experiment. Response surface methodology (RSM), an experimental method suitable for nonlinear mathematical models, considers experimental random errors and fits complex unknown functional relations with polynomial functions.

Therefore, the RSM was further used to explore the relationship between each parameter and Ra value. Then, a response surface regression mathematical model was established, and the exact value of surface roughness was obtained.

\subsection{Theoretical Analysis}

RSM is the product of a combination of mathematical and statistical methods, using regression methods to approximate the relationship between input and output quantities by means of polynomials [25]. Then, the functional relationship is established to quantitatively analyze the effect of input quantities and their interactions on the output values. The ultimate goal is to optimize that output value. Its second-order polynomial is based on the expansion of Taylor's formula, which extends from a single variable to multiple variables. The specific formula is shown in Formula (7) [26]:

$$
y=\beta_{0}+\sum_{i=1}^{k} \beta_{i} x_{i}+\sum_{i=1}^{k} \beta_{i i} x_{i}^{2}+\sum_{i<j}^{k} \beta_{i j} x_{i} x_{j}+\varepsilon
$$

In the formula, $\mathrm{k}$ represents the total number of input parameters, $x_{i}$ and $x_{j}$ refer to the $i$-th and $j$-th input parameters, $\beta_{\mathrm{i}}$ and $\beta_{\mathrm{ii}}$ denote the linear and quadratic effect coefficients respectively, $\beta_{\mathrm{ij}}$ is the interaction coefficient, and $\varepsilon$ is the error term.

\subsection{BBD Experimental Design and Discussion}

The widely used Box-Behnken Design experiment (BBD) is an experimental method based on response surface theory and is widely used $[17,18,26]$. A three-factor, threelevel BBD experiment was established to explore the relationship between each parameter and the response target. The experiment was conducted under the conditions of $20 \mathrm{~mm}$ extension and 600 mesh oilstone. The specific experimental parameters are listed in Table 5, and the analysis of variance (ANOVA) results are listed in Table 6. 
Table 5. BBD experimental design.

\begin{tabular}{cccc}
\hline Factors & $\begin{array}{c}\text { Grinding Head } \\
\text { Rotation Speed, } \mathbf{V}_{\mathbf{1}} \\
(\mathbf{r} / \mathbf{m i n})\end{array}$ & $\begin{array}{c}\text { Workpiece } \\
\text { Reciprocation Speed, } \\
\mathbf{V}_{\mathbf{2}}(\mathbf{m} / \mathbf{m i n})\end{array}$ & $\begin{array}{c}\text { Single Grinding } \\
\text { Depth, } \mathbf{\Delta x}(\mathbf{m m})\end{array}$ \\
\hline Level 1 & 50 & 30 & 0.005 \\
Level 2 & 100 & 40 & 0.015 \\
Level 3 & 150 & 50 & 0.025 \\
\hline
\end{tabular}

Table 6. ANOVA of experimental results.

\begin{tabular}{|c|c|c|c|c|c|c|}
\hline Items & $\begin{array}{c}\text { Sum of } \\
\text { Squares }\left(10^{-3}\right)\end{array}$ & df & $\begin{array}{c}\text { Mean Square } \\
\left(10^{-3}\right)\end{array}$ & F-Value & $p$-Value & Significance \\
\hline Model & 13.395 & 9 & 1.488 & 68.0925 & $<0.0001$ & $\begin{array}{l}\text { Extremely } \\
\text { significant }\end{array}$ \\
\hline A-Grinding rotation speed & 0.545 & 1 & 0.545 & 24.9118 & $<0.0001$ & \\
\hline $\begin{array}{l}\text { B-Reciprocating velocity of } \\
\text { workpiece }\end{array}$ & 0.032 & 1 & 0.032 & 1.4641 & 0.2656 & Not significant \\
\hline $\mathrm{C}$-Single grinding depth & 6.962 & 1 & 6.962 & 318.522 & $<0.0001$ & \\
\hline $\mathrm{AB}$ & 0.342 & 1 & 0.342 & 15.6585 & 0.0055 & \\
\hline $\mathrm{AC}$ & 0.156 & 1 & 0.156 & 7.1487 & 0.0318 & \\
\hline $\mathrm{BC}$ & 0.056 & 1 & 0.056 & 2.5735 & 0.1527 & Not significant \\
\hline $\mathrm{A}^{2}$ & 2.015 & 1 & 2.015 & 92.1805 & $<0.0001$ & \\
\hline $\mathrm{B}^{2}$ & 0.995 & 1 & 0.995 & 45.5379 & 0.0003 & \\
\hline$C^{2}$ & 1.748 & 1 & 1.748 & 79.9721 & $<0.0001$ & \\
\hline Residual & 0.153 & 7 & 0.022 & & & \\
\hline Lack of Fit & 0.153 & 3 & 0.051 & & & \\
\hline Pure Error & $<0.0001$ & 4 & $<0.0001$ & & & \\
\hline Cor Total & 13.548 & 16 & & & & \\
\hline
\end{tabular}

As shown in Figure 8a,c,e, all response surface openings are upward, and the surface roughness Ra values are in a more obvious quadratic parabolic relationship with the three parameters. As can be seen in Figure 8a,c, the graph has a large color variation and the largest slope with the most significant change in the single grinding depth. It suggests that when the grinding head speed and reciprocating speed are given, the single grinding depth has the greatest effect on the roughness. Shaowu et al. [27] investigated that as the feed increases, the effective grinding edge on the surface of the oilstone increases, the average cutting thickness of the single grain oilstone on the workpiece surface also increases, and the grinding groove width on the workpiece surface increases. In Figure $8 b$, we can see that the isoline is elliptical, which shows that the interaction of single grinding depth and grinding head speed has a significant impact on the Ra value. The Ra value grows with the increase of single grinding depth and decreases with the growth of grinding head speed, and then tends to be dynamic and stable. This is because the greater the speed of the grinding head, the more cutting edges are involved in the surface of the workpiece per unit of time. With the relatively low speed, the cutting layer of each cutting edge is relatively low, and the surface obtained will be finer. However, as the rotational speed continues to increase, the honing heat increases fast, the oilstone wears and clogs the air hole, the self-sharpening decreases, and the effective cutting-edge number tends to stabilize. As shown in Figure 8d, the contours are nearly circular, indicating that the single grinding depth and reciprocating speed have a relatively independent influence on roughness, and their interaction effects are not pronounced. As can be seen in Figure 8e, the surface is low in the middle and slightly high around it, with little color difference, and tends to be stable, indicating that the rotational speed and reciprocating speed alone have little effect on the roughness Ra value. From Figure 8f, the contours have an elliptical distribution, indicating that the interaction of grinding head rotation speed and reciprocating speed significantly affects the roughness value. When the grinding head rotation speed tends to 
$113 \mathrm{r} / \mathrm{min}$ and the reciprocating speed tends to $41 \mathrm{~m} / \mathrm{min}$, the roughness Ra value tends to be the smallest. This is because the roughness is affected by the honing angle formed by reciprocation speed and rotation speed $[28,29]$. At this time, the honing angle is non-integer $19.9^{\circ}$, the grinding head rotation speed $113 \mathrm{r} / \mathrm{min}$ and the reciprocating speed $41 \mathrm{~m} / \mathrm{min}$ are prime numbers, and the ratio of the honing head reciprocating times per minute to the rotating speed is non-integer 1.73. It shows that the honing head diverges a certain angle relative to the workpiece in the circumferential direction between two strokes. In this way, the trajectory of single abrasive grains on the bore wall is not repeated. The ineffective grinding and overlapping grinding are reduced, the grinding gouges on the workpiece surface are finer, and the roughness Ra value reduces.

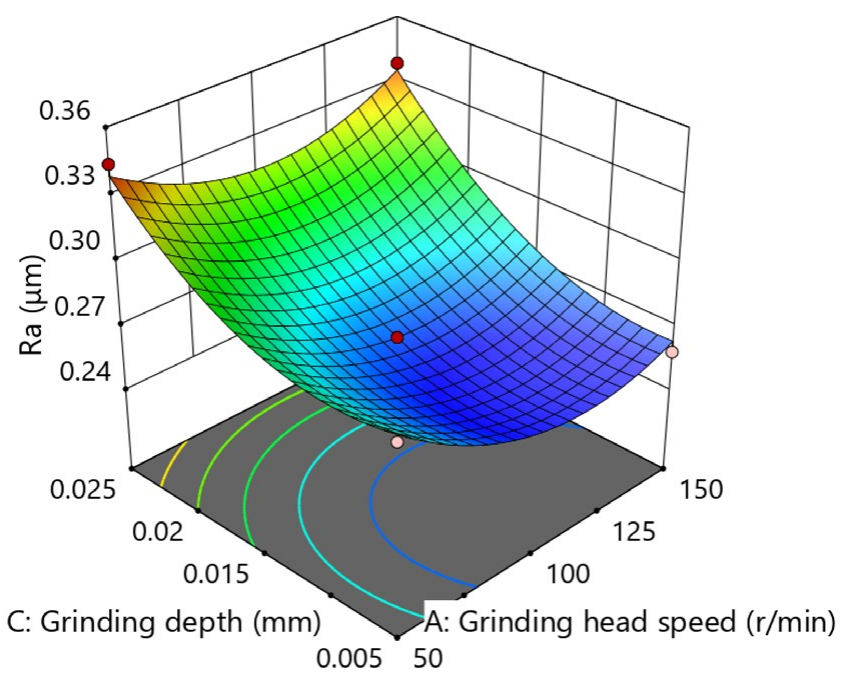

(a)

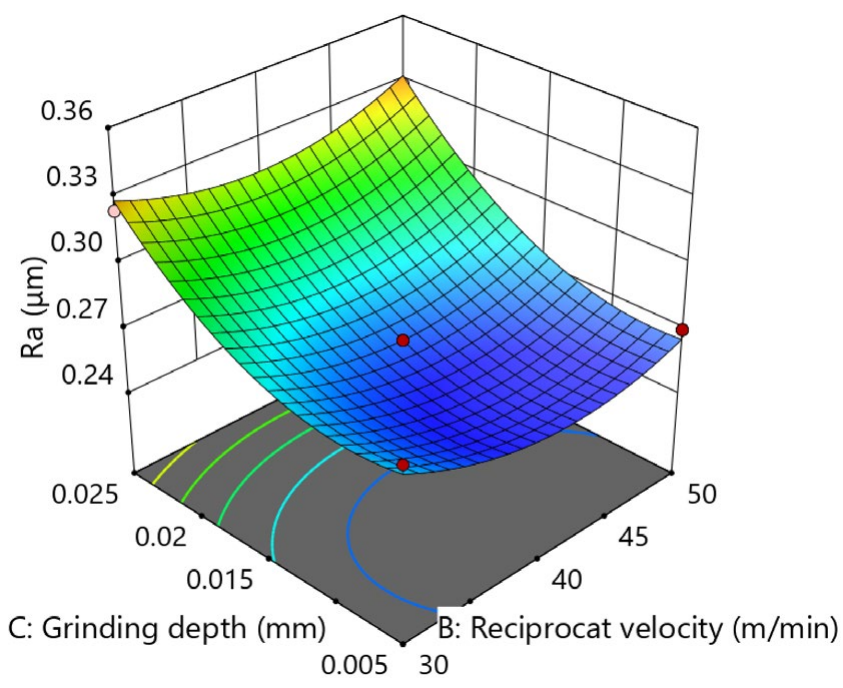

(c)

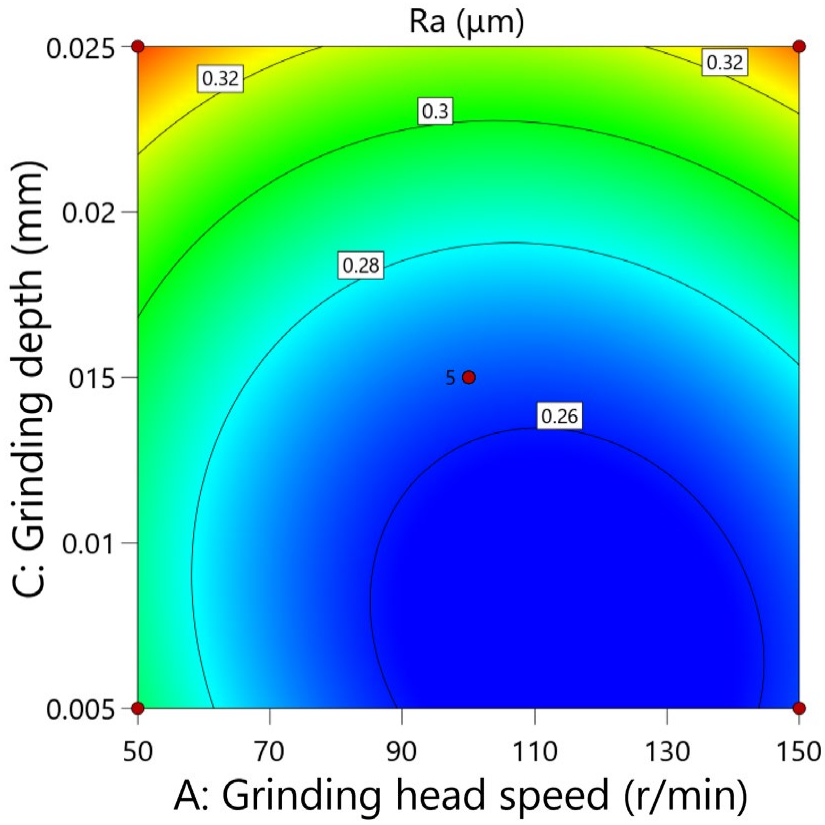

(b)

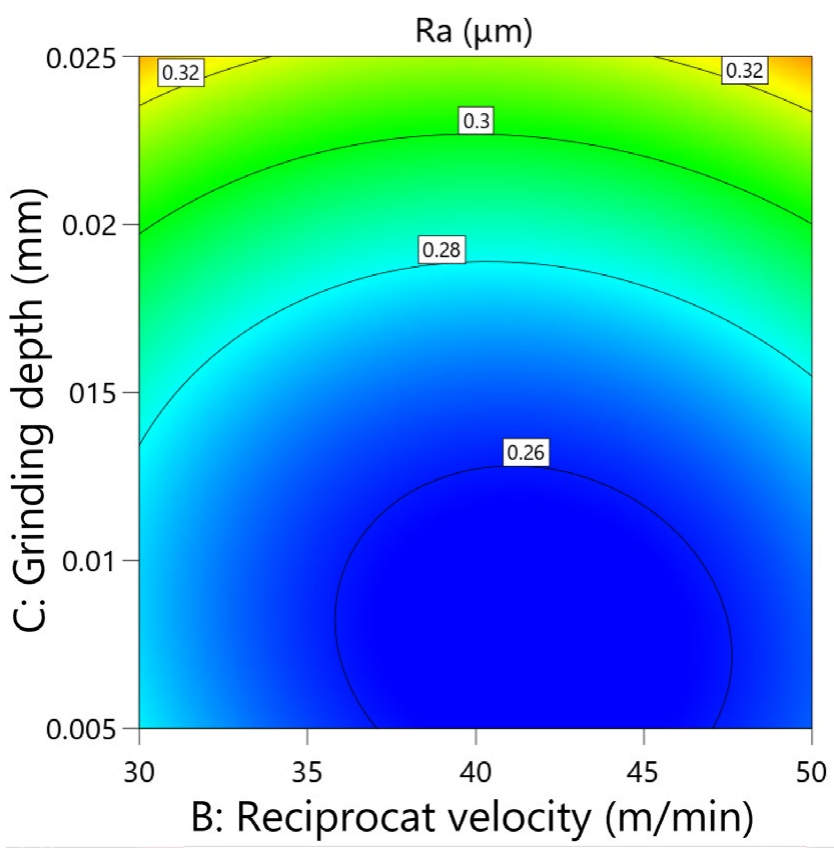

(d)

Figure 8. Cont. 


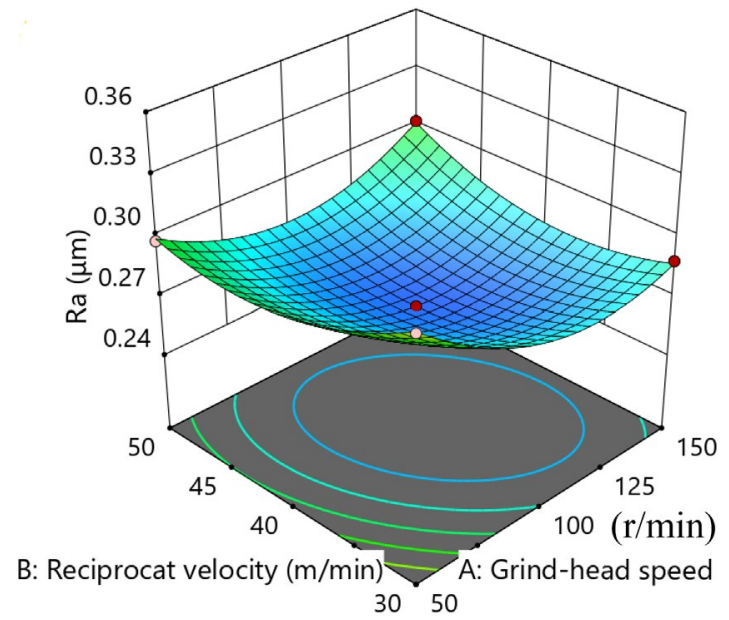

(e)

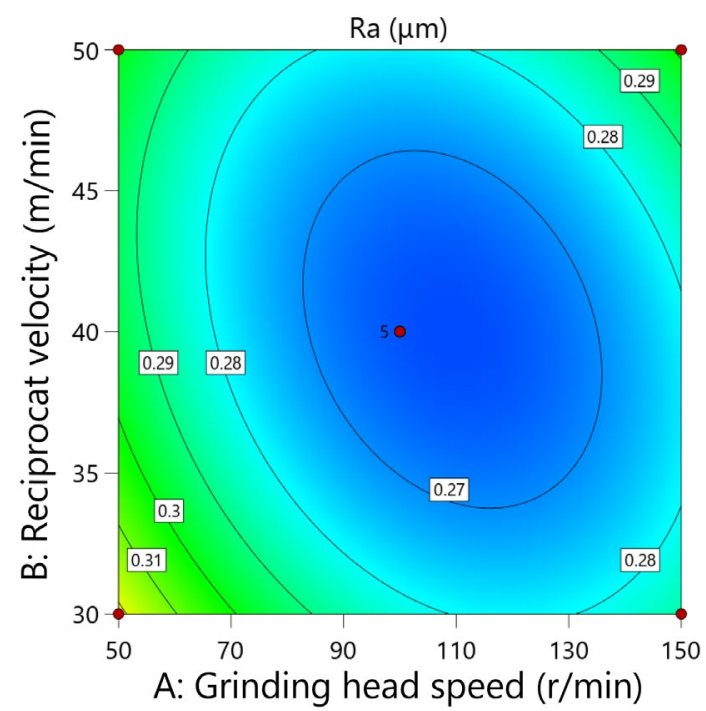

(f)

Figure 8. Response surface plot and projected contour plot of interaction. (a) Response surface of grinding depth and grinding head speed when the reciprocat velocity is $40 \mathrm{~m} / \mathrm{min}$. (b) Contour of grinding depth and grinding head speed when the reciprocating velocity is $40 \mathrm{~m} / \mathrm{min}$. (c) Response surface of grinding depth and reciprocating velocity when the grinding head speed is $97 \mathrm{r} / \mathrm{min}$. (d) Contour of grinding depth and reciprocating velocity when the grinding head speed is $97 \mathrm{r} / \mathrm{min}$. (e) Response surface of grinding head speed and reciprocating velocity when the grinding depth is $0.010 \mathrm{~mm}$. (f) Contour of grinding head speed and reciprocating velocity when the grinding depth is $0.010 \mathrm{~mm}$.

\subsection{Build Optimization Model}

The significance of each item in the ANOVA is a criterion for judging the model parameters. $p$-value $<0.05$ in the ANOVA table (listed in Table 6) indicates that the more significant it is, the greater the influence of the target variable on the optimization of the model. When the $p$-value $>0.05$, it represents a non-significant effect. The $p$-values of $C$ (single grinding depth), A (grinding head speed), A2, and $C^{2}$ are less than 0.0001 , and the $p$-value of $\mathrm{B}^{2}$ is 0.0003 , which denotes that the linear terms $\mathrm{C}$ and $\mathrm{A}$ and the squared terms $A^{2}, B^{2}$, and $C^{2}$ have a highly significant effect on the model. $p$-values of interaction items $A B$ and $A C$ are less than 0.001, which indicates that interaction has a significant effect on the model. Therefore, by incorporating the extremely significant factors and significant factors into the response surface regression model, it can be concluded that the mathematical optimization model is a second-order model. Then, according to Formula (7), the second-order response surface optimization model was calculated by using the least square method and Matlab software. The optimization model is shown in Formula (8):

$$
\begin{gathered}
\mathrm{R}_{\mathrm{a}}=0.7398-0.002843 \mathrm{~A}-0.0149 \mathrm{~B}-5.9125 \mathrm{C}+1.9 \times 10^{-5} \mathrm{AB} \\
\quad+0.0125 \mathrm{AC}+8.75 \times 10^{-6} \mathrm{~A}^{2}+1.54 \times 10^{-4} \mathrm{~B}^{2}+203.75 \mathrm{C}^{2}
\end{gathered}
$$

The $\mathrm{R}^{2}$ value is an evaluation index of the model fitting effect. The calculated $\mathrm{R}^{2}$ value of this model is 0.9887 , and the adjusted $R^{2}$ value is 0.9742 , both of which are greater than 0.95 , indicating that the model fits well.

\section{Optimization Results and Experimental Verification}

The optimal combination of process parameters for roughness, $\mathrm{Ra}$, was obtained under the conditions of $20 \mathrm{~mm}$ extension and 600 mesh oilstone $\left(\mathrm{V}_{1}=113 \mathrm{r} / \mathrm{min}, \mathrm{V}_{2}=41 \mathrm{~m} / \mathrm{min}\right.$, and $\Delta \mathrm{x}=0.007 \mathrm{~mm}$ ), with the corresponding roughness $\mathrm{Ra}$ value of 0.244 .

To verify the predicted optimal process parameters, experiments were arranged for verification. The parameters processed on-site were used as Group 1, and the predicted optimal parameter combination was selected as Group 2. The other five comparison 
experiments were random data near the optimal parameter combination. The experimental arrangement and measurement results are shown in Table 7 , and the results of the validation experiments are presented in Figure 9. The root mean square error between the measured and the calculated value is 0.012 , which indicates that the model predicts well. The results suggest that the Ra value of the optimal parameter combination is better than other experimental results in Table 6. After optimization, the Ra value decreased by $25.8 \%$, and the surface quality significantly improved.

Table 7. Experimental arrangement and measurement results.

\begin{tabular}{ccccc}
\hline Experiment & $\begin{array}{c}\text { Grinding Head Speed } \\
(\mathbf{r} / \mathbf{m i n})\end{array}$ & $\begin{array}{c}\text { Reciprocating Velocity } \\
(\mathbf{m} / \mathbf{m i n})\end{array}$ & $\begin{array}{c}\text { Single Grinding } \\
\text { Depth }(\mathbf{m m})\end{array}$ & Ra $(\boldsymbol{\mu m})$ \\
\hline 1 & 100 & 30 & 0.025 & 0.33 \\
2 & 113 & 41 & 0.007 & 0.245 \\
3 & 120 & 45 & 0.008 & 0.255 \\
4 & 120 & 35 & 0.008 & 0.252 \\
5 & 120 & 45 & 0.01 & 0.251 \\
6 & 100 & 40 & 0.005 & 0.255 \\
\\
\hline
\end{tabular}

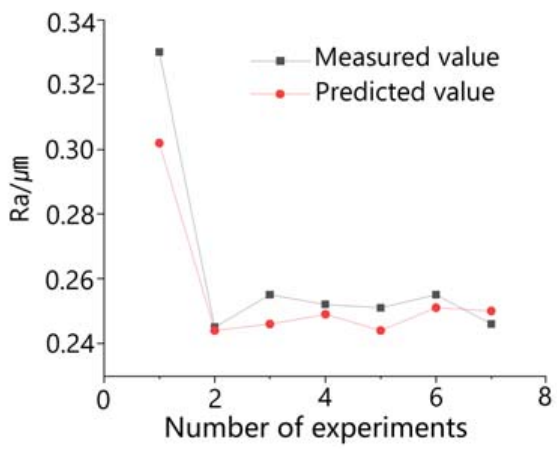

Figure 9. Comparison between measured and predicted value.

A laser confocal microscope (Name: Shape measurement laser microscope, model: VK-X1000, Origin: KEYENCE Co., Ltd., Osaka, Japan) was used to visually observe the surface morphology before and after optimization. A $20 \times$ objective lens was selected to observe a large field of view. The observation equipment is shown in Figure 10. The 3D surface morphology effects of the workpiece before optimization (Group 1) and after optimization (Group 2) are shown in Figure 11. Compared with the projection graph, the surface after optimization was finer and more uniform than before.

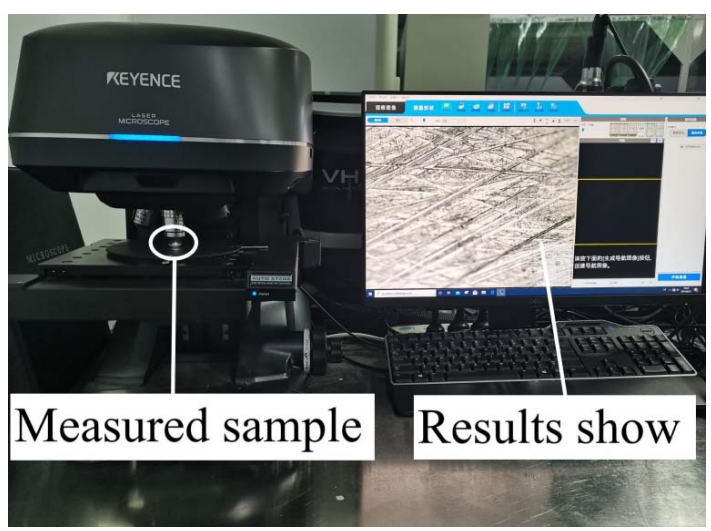

Figure 10. Laser confocal microscope. 


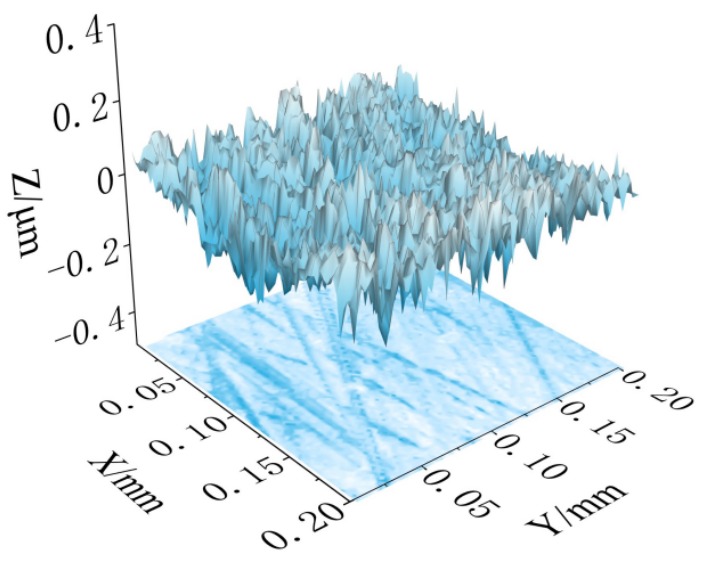

(a)

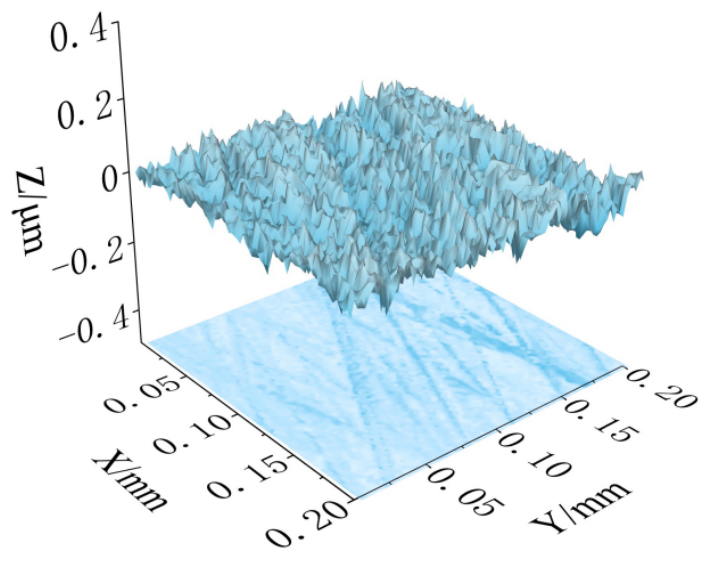

(b)

Figure 11. (a) Surface morphology before optimization, (b) surface morphology after optimization.

\section{Conclusions}

Based on GRA and RSM, this paper analyzed the influence of honing parameters of carburized alloy steel on surface quality and obtained the optimal honing parameters with the minimum roughness $\mathrm{Ra}$ value. The specific conclusions are as follows:

(i) Analysis by orthogonal experiments showed that the surface roughness Ra value of the carburized hole decreased with the increase of the honing head extension. When the extension was $20 \mathrm{~mm}$, the cylinder of the carburized hole was the best, and there was no problem with waist bulge and bell mouth.

(ii) Based on grey relational grade, the SNR of surface roughness ( $\mathrm{Ra}$ ) for different parameter combinations was analyzed, and the order of influence on roughness $(\mathrm{Ra})$ was: average grain size of oilstone $>$ single grinding depth $>$ grinding head speed $>$ workpiece reciprocating speed.

(iii) The BBD experiments based on the response surface method showed that the roughness Ra value decreased with the decrease of the single grinding depth. It decreased with the increase of the grinding head speed and then tended to stabilize dynamically. The interaction effect of grinding head speed and reciprocating speed was significant.

(iv) The optimized mathematical model of Ra was established under the condition of $20 \mathrm{~mm}$ extension and 600 mesh oilstone, and the combination of parameters $\left(\mathrm{V}_{1}=113 \mathrm{r} / \mathrm{min}, \mathrm{V}_{2}=41 \mathrm{~m} / \mathrm{min}\right.$, and $\left.\Delta \mathrm{x}=0.007 \mathrm{~mm}\right)$ with minimum Ra $(0.244 \mu \mathrm{m})$ was calculated. Compared with that before optimization, the roughness quality was improved by $25.8 \%$.

Author Contributions: T.T., research on the status of domestic and international research; writing of first draft and translation; etc. C.L., review and revision; Funding support; researching and investigation process, etc. R.W., experimental supervision; on-site implementation guidance; etc. All authors have read and agreed to the published version of the manuscript.

Funding: This work was supported by the Scientific Research Fund of Hunan Provincial Education Department (20C0168, 20B068), the Changsha Municipal Natural Science Foundation (kq2007085), and the Enterprise-level Key Project (G41820001).

Institutional Review Board Statement: Not applicable.

Informed Consent Statement: Not applicable.

Data Availability Statement: No new data were created or analyzed in this study. Data sharing is not applicable to this article.

Conflicts of Interest: The authors declare no conflict of interest. The funders had no role in the design of the study, in the collection, analyses, or interpretation of data, in the writing of the manuscript, or in the decision to publish the results. 


\section{References}

1. Huang, X. Research on the Grinding Burn of the Ultrahigh Strength Steel AerMet100. Chin. J. Mech. Eng. 2015, 51, 184-190. [CrossRef]

2. Zahouani, H.; EL Mansori, M. Multi-scale and multi-fractal analysis of abrasive wear signature of honing process. Wear 2017, 376, 178-187. [CrossRef]

3. Klocke, F. Manufacturing Processes 2: Grinding, Honing, Lapping; Springer: Berlin/Heidelberg, Germany, 2009.

4. Moos, U.; Bähre, D. Analysis of Process Forces for the Precision Honing of Small Bores. Procedia CIRP 2015, 31, 387-392. [CrossRef]

5. Lu, Q.; Zhou, G.; Zhao, F.; Ren, Y.; Li, L.; Luan, X.; Sutherland, J.W. Topology optimization of oilstone components considering carbon emissions associated with honing processes. J. Clean. Prod. 2019, 225, 181-195. [CrossRef]

6. Grover, V.; Singh, A.K. Improved magnetorheological honing process for nanofinishing of variable cylindrical internal surfaces. Mater. Manuf. Process. 2017, 33, 1177-1187. [CrossRef]

7. Droeder, K.; Hoffmeister, H.-W.; Grosse, T. Force-controlled form honing using a piezo-hydraulic form honing system. CIRP Ann. 2017, 66, 317-320. [CrossRef]

8. Buj-Corral, I.; Álvarez-Flórez, J.; Domínguez-Fernández, A. Acoustic emission analysis for the detection of appropriate cutting operations in honing processes. Mech. Syst. Signal Process. 2018, 99, 873-885. [CrossRef]

9. Buj-Corral, I.; Vivancos-Calvet, J.; Setien, I.; Sebastian, M.S. Residual stresses induced by honing processes on hardened steel cylinders. Int. J. Adv. Manuf. Technol. 2017, 88, 2321-2329. [CrossRef]

10. Ma, S.; Liu, Y.; Wang, Z.; Wang, Z.; Huang, R.; Xu, J. The Effect of Honing Angle and Roughness Height on the Tribological Performance of CuNiCr Iron Liner. Metals 2019, 9, 487. [CrossRef]

11. Barros, G.H.C.; Schramm, C.R.; Franco, S.D.; Arantes, L.J.; Arencibia, R.V. Effect of grain size and number of strokes on Rk parameters and emptiness coefficient in honing process. Int. J. Adv. Manuf. Technol. 2019, 103, 3717-3734. [CrossRef]

12. Muratov, R.A.; Muratov, K.R.; Gashev, E.A.; Ablyaz, T.R. Control of Surface Roughness in Raster Honing. Russ. Eng. Res. 2021, 41, 442-444. [CrossRef]

13. Yang, C.; Su, H.; Gao, S.; Fu, Y.; Ding, W.; Xu, J. Surface quality and geometric accuracy control of fuel nozzle single-pass honing. Int. J. Adv. Manuf. Technol. 2021, 114, 3325-3336. [CrossRef]

14. Box, G.E.P.; Wilson, K.B. On the Experimental Attainment of Optimum Conditions; Springer: New York, NY, USA, 1992.

15. Nguyen, T.-T.; Vu, T.-C.; Duong, Q.-D. Multi-responses optimization of finishing honing process for surface quality and production rate. J. Braz. Soc. Mech. Sci. Eng. 2020, 42, 604. [CrossRef]

16. Sadizade, B.; Araee, A.; Oliaei, S.N.B.; Farshi, V.R. Plateau honing of a diesel engine cylinder with special topography and reasonable machining time. Tribol. Int. 2020, 146, 106204. [CrossRef]

17. Lawrence, K.D.; Ramamoorthy, B. Multi-surface topography targeted plateau honing for the processing of cylinder liner surfaces of automotive engines. Appl. Surf. Sci. 2016, 365, 19-30. [CrossRef]

18. Liu, D.; Huang, C.; Wang, J.; Zhu, H.; Yao, P.; Liu, Z. Modeling and optimization of operating parameters for abrasive waterjet turning alumina ceramics using response surface methodology combined with Box-Behnken design. Ceram. Int. 2014, 40, 7899-7908. [CrossRef]

19. Ciggin, A.S.; Sarica, E.S.; Doğruel, S.; Orhon, D. Impact of ultrasonic pretreatment on Fenton-based oxidation of olive mill wastewater-Towards a sustainable treatment scheme. J. Clean. Prod. 2021, 313, 127948. [CrossRef]

20. Sindhu, D.; Thakur, L.; Chandna, P. Parameter Optimization of Rotary Ultrasonic Machining on Quartz Glass Using Response Surface Methodology (RSM). Silicon 2019, 12, 629-643. [CrossRef]

21. Kanchana, J.; Prasath, V.; Krishnaraj, V. Multi response optimization of process parameters using grey relational analysis for milling of hardened Custom 465 steel. Procedia Manuf. 2019, 30, 451-458. [CrossRef]

22. Wu, X.; Yang, Y.; Tong, X.; Shu, X.; Li, Y. The Grey Theory Combining the Taguchi Method for the Best Parameters: A Case Study of Polishing M300 Steel. Math. Probl. Eng. 2019, 2019, 7306841. [CrossRef]

23. Tung, L.A.; Pi, V.N.; Lien, V.T.; Hong, T.T.; Hung, L.X.; Long, B.T. Optimization of dressing parameters of grinding wheel for 9CrSi tool steel using the taguchi method with grey relational analysis. In Proceedings of the IOP Conference Series: Materials Science and Engineering, Bangkok, Thailand, 21-23 January 2019.

24. Wang, Q.; Yang, J. Experimental Design and Analysis, 2nd ed.; China Agricultural Press: Beijing, China, 2007.

25. Wang, R. Experimental Design and Analysis, 3rd ed.; China Statistics Press: Beijing, China, 1998.

26. Zhang, Z.; Yao, P.; Huang, C.; Wang, J.; Xue, D.; Deng, W.; Zhang, Z. Investigation and modeling of microgrooves generated on diamond grinding wheel by abrasive waterjet based on Box-Behnken experimental design. Int. J. Adv. Manuf. Technol. 2018, 100, 321-332. [CrossRef]

27. Gao, S.; Yang, C.; Xu, J.; Fu, Y.; Zhou, X.; Yan, W.; Zou, P. Study on Surface Roughness of Nickel-based Supperalloy during Honing. China Mech. Eng. 2017, 28, 223-232. [CrossRef]

28. El Mansori, M.; Goeldel, B.; Sabri, L. Performance impact of honing dynamics on surface finish of precoated cylinder bores. Surf. Coat. Technol. 2013, 215, 334-339. [CrossRef]

29. Mezghani, S.; Demirci, I.; Yousfi, M.; El Mansori, M. Mutual influence of crosshatch angle and superficial roughness of honed surfaces on friction in ring-pack tribo-system. Tribol. Int. 2013, 66, 54-59. [CrossRef] 